\title{
Decidir entre todos Una propuesta de análisis en torno a los mecanismos de deliberación y decisión en ámbitos colectivos
}

\section{Matías Triguboff ${ }^{1,2}$ *}

1 CONICET, Universidad de Buenos Aires, Buenos Aires, Argentina. 2 Universidad Nacional Arturo Jauretche, Buenos Aires, Argentina. Correo electrónico: mtriguboff@yahoo.com.ar
Recibido

agosto de 2017

Aceptado

enero de 2018

\section{Resumen}

El artículo retoma la discusión sobre las formas de organización y decisión de los movimientos sociales a partir del estudio de las reuniones plenarias de las asambleas populares conformadas en Argentina entre 2001 y 2006. Desde un enfoque antropológico relacional, analiza cómo estas eran un lugar de intercambio más que un espacio de decisión común, y cómo su dinámica era afectada por distintas tensiones y diferenciaciones. Muestra que los distintos sentidos en torno a la dinámica de las reuniones plenarias no se circunscribían a una delimitación de un criterio metodológico común de funcionamiento, sino que implicaban una concepción política sobre las asambleas, que establecían ciertas relaciones de poder entre sus integrantes.

\section{Deciding all together. Reflections on the mechanisms of delibera- tion and decision in collective organization}

\begin{abstract}
The article retakes the discussion on the forms of organization and decision of social movements, through the study of plenary meetings of the popular assemblies formed in Argentina between 2001 and 2006. From an anthropological relational approach, it analyzes how they were a place for meeting and exchange rather than a common decision space, and how their dynamics were affected by different tensions and differentiations. It shows how different meanings surrounding the dynamics of the plenary meetings were not confined to delimiting a common methodological criterion of functioning, but involved a political conception regarding assemblies, establishing certain power relations among its members.
\end{abstract}

\section{Palabras clave}

Asambleas populares; Acción colectiva; Toma de decisiones; Reuniones plenarias; Relaciones de poder

\section{Key words}

Popular assemblies; Collective action; Decision-making; Plenary meetings; Power relations 


\section{Decidir juntos. Uma proposta de analise ao redor dos mecanismos de deliberação e decisão em âmbitos coletivos}

Palavras-chave

Assembleias populares; Ação coletiva; Tomada de decisão; Reuniões plenárias; Relações de poder
1. Entre las asambleas podía observarse una amplia diversidad en sus denominaciones, que variaban entre "barriales", "populares", "vecinales", "vecinos autoconvocados”, según las estrategias desarrolladas en sus comienzos con relación al barrio y a otras organizaciones sociales y políticas (Pérez, Armelino y Rossi, 2005; Triguboff, 2005). Por ello, utilizaremos el concepto asamblea para poder contener estas diferentes denominaciones. Utilizo comillas para referencias textuales y bastardillas para términos nativos.

\section{Resumo}

O artigo retoma a discussão sobre as formas de organização e determinação dos movimentos sociais, a partir do estudo das reuniões plenárias das assembleias populares formadas na Argentina entre 2001 e 2006. Partindo de uma abordagem antropológica relacional, ele analisa como estes eram um ponto de encontro e troca, em vez de um espaço de decisão comum, e como a sua dinâmica foi afetada por várias tensões e diferenciações. Ele mostra como os diferentes sentidos em torno da dinâmica de reuniões plenárias não se limitaram a uma definição de uma abordagem metodológica comum de operação, mas que envolveram uma concepção política em relação às assembleias, que estabeleceram determinadas relações de poder entre seus membros.

\section{Introducción}

Uno de los ámbitos más valorados por los integrantes de las organizaciones sociales es, generalmente, el espacio de la toma de decisiones. Por consiguiente, uno de los ejes comunes de análisis es la forma de organización y decisión que se da en los ámbitos colectivos. Distintas investigaciones han trabajado sobre las "formas democráticas de participación y decisión colectivas" que de diverso modo ponderan la "democracia directa", la "horizontalidad", el "privilegio del consenso" o la "autonomía" que han caracterizado a los movimientos sociales y otras formas de acción colectiva contemporáneas (De Sousa Santos, 2005; Zibechi y Hardt, 2013). En este artículo propongo analizar las reuniones plenarias de las asambleas ${ }^{1}$ populares conformadas en Argentina entre 2001 y 2006.

Las asambleas fueron parte de los procesos de movilización popular de los años 2001 y 2002. Una de las características distintivas de esos días fue la recuperación de un formato común utilizado en distintas organizaciones políticas y sociales: la reunión en asamblea. Esta permitía, según sus protagonistas, una forma de intercambio y discusión abierta en las esquinas de los barrios de la Ciudad de Buenos Aires, características que se convirtieron en fuente de legitimidad para su funcionamiento y desarrollo. Al mismo tiempo, esta forma constituyó un ámbito para el surgimiento de acciones e iniciativas políticas, de instancias de coordinación con otras organizaciones y sectores sociales, así como para la organización de demandas hacia el Estado y proyectos para el barrio.

En general, las investigaciones que analizaron el modelo de organización y toma de decisiones de las asambleas se focalizaron en describir su "forma horizontal" (Di Marco, Palomino, Méndez, Altamirano y Libchaber de Palomino, 2003; Ouviña, 2002; Dinnerstein, 2004; Dri, 2006; Fernández, 2006). Estudiaron cómo, a diferencia de las organizaciones políticas "tradicionales" como partidos políticos o sindicatos, estas objetaron las relaciones jerárquicas entre sus integrantes y se orientaron hacia formas de decisión por consenso, y en ocasiones, por mayoría.

Enfatizaron que las asambleas adoptaron una "radicalización novedosa" por medio de la búsqueda de "horizontalidad", "soberanía”, "autonomía”, "nuevos modos de organización” (Dri, 2006; Fernández, 2006) y expresaron "una práctica de la democracia 
directa o radical" por su manera de deliberar y decidir (Di Marco et al., 2003; Ouviña, 2002; Dinnerstein, 2004). Otros autores estudiaron las diferentes características que estas tomaron según su composición de clase, pero no indagaron sobre las tensiones y particularidades de las reuniones y los procesos de toma de decisión (Brandone, Castañeda y Román, 2017).

Sin embargo, ya en 2002, otros autores como Svampa y Corral (2002) habían planteado que las asambleas tuvieron dificultades en instituirse como un lugar de construcción de consensos, a pesar del ejercicio de una "suerte de democracia participativa" en el trabajo barrial y en las discusiones internas. Señalaron la prevalencia de prácticas de activistas partidarios y del "saber experto" de los profesionales como uno de los límites para que se convirtieran en un "verdadero espacio de deliberación política".

Aún focalizando en las diferencias, Pérez, Armelino y Rossi (2005) se centraron exclusivamente en los formatos de organización para la toma de decisiones, y propusieron dos tipos según la denominación que tuvieron las asambleas por sus propios integrantes. En las "asambleas populares" distinguieron el rol rotativo del moderador. Cada sesión era "soberana"; las comisiones solo se ocupaban de cuestiones operativas y se intentaba evitar el voto individual en busca de la construcción de consensos. En las "asambleas de vecinos", las comisiones adquirían mayor relevancia; el tipo de demanda era fundamentalmente "vecinalista"; se basaban en la regla de la mayoría y el voto era individual. No se buscaba la unificación de criterios, sino un debate operativo de las propuestas elevadas por las comisiones. Esa diferenciación entre tipos de asamblea también repercutiría en las posibilidades de continuidad y de influencia territorial y política (Mauro y Rossi, 2015).

Como podemos observar, uno de los ejes de análisis de los estudios sobre asambleas fue su forma de organización, definida como "horizontal", y la búsqueda del consenso para la toma de decisiones. Más allá de los matices presentados, los autores mencionados tendieron a homogenizar, naturalizar y generalizar las dinámicas de funcionamiento de ellas y a pensarlas como parte de un mismo "movimiento".

Una mirada global sobre las investigaciones mencionadas permite observar que estas no tuvieron en cuenta cómo operaron cotidianamente las prácticas de funcionamiento de las asambleas; no analizaron los procesos de interacción ni la diversidad de sentidos puestos en juego. Al mismo tiempo, más allá de destacar la influencia diferenciada de distintos asambleístas (Fernández, 2006), como los activistas y los profesionales (Svampa y Corral, 2002), los autores mencionados no profundizaron respecto de cómo se desarrollaban la reunión plenaria, las relaciones entre los integrantes, el uso de la palabra y las relaciones de desigualdad según las características de cada asambleísta.

Desde un enfoque antropológico relacional, que permite recuperar la unidad entre representación y práctica, y entre saber y acción, planteo indagar en las prácticas cotidianas, las relaciones sociales y los sentidos que cotidianamente ponen en juego los sujetos (Gledhill, 2000; Grimberg, Ernandez y Manzano, 2011). Abordo el estudio de las asambleas en su doble carácter, como proceso político y como experiencia de vida que involucra a sujetos y colectivos. La categoría de vida cotidiana entendida como "un conjunto de prácticas, relaciones, significaciones diversas y heterogéneas que constituyen sujetos concretos al interior de una realidad concreta" (Achilli, 1993, p. 11) me permite captar las mediaciones entre las relaciones cotidianas de los sujetos y sus significaciones y otros procesos institucionales y estructurales.

Este trabajo forma parte de los resultados de una tesis de doctorado ya finalizada sobre asambleas en la ciudad de Buenos Aires. A nivel teórico, se inscribe en una línea de investigación sobre procesos de movilización social y acción colectiva que plantea un 
enfoque que descentra la mirada del momento de la protesta para indagar las prácticas cotidianas, las relaciones sociales y los sentidos que cotidianamente ponen en juego los sujetos protagonistas (Grimberg, 2009; Fernández Álvarez, 2012; Manzano, 2013; Triguboff, 2015). Frente a miradas que centraron su análisis en las potencialidades y dificultades de las asambleas para constituirse en actor colectivo ("movimiento"), y que focalizaron sus acciones de confrontación con el Estado, sus identidades, sus repertorios de acción colectiva y el impacto de sus demandas en el sistema político (Fernández, 2006; Svampa, 2008; Mauro y Rossi, 2015), propone estudiar cómo en el contexto de los procesos políticos, de la diversidad de trayectorias sociales y de vida pueden entenderse los sentidos y los alcances de una práctica colectiva.

En términos empíricos, la investigación está basada en un trabajo de campo intensivo entre 2002 y 2007 en la ciudad de Buenos Aires, compuesto por observación participante, treinta y cinco entrevistas en profundidad, análisis de narrativas, reconstrucción de trayectorias de vida sobre la base de dichas narrativas y análisis de fuentes secundarias.

El trabajo de campo se dividió en dos etapas. En una primera etapa, desde un nivel intermedio de análisis -entre 2002 y 2003-, examiné la dinámica de funcionamiento de las reuniones de distintas asambleas de la ciudad de Buenos Aires, algunas de sus actividades y el funcionamiento cotidiano del espacio colectivo. Luego de un acercamiento general, seleccioné dos asambleas para estudiar en profundidad, focalizando en aspectos de la vida cotidiana y la trayectoria de vida de algunos de sus integrantes. Para escoger ambos casos, tuve en cuenta su ubicación territorial, composición y principales características, al considerar que debían ser ejemplos significativos para analizarlas. También presté especial atención sobre el tipo de actividades que realizaban, si habían seguido funcionando o no, su relación con el Estado y los partidos políticos, y si tenían o no un local. Entre fines de 2005 y principios de 2007, realicé la última serie de entrevistas. En esta etapa, gran parte de las personas a las que entrevisté ya no formaban parte de ninguna asamblea. Así pude trabajar sobre las percepciones y balances que ellos mismos efectuaban.

En este caso, retomo la discusión sobre las formas de organización y decisión de los movimientos sociales. Para ello, me centro en las reuniones plenarias semanales como una dimensión política de las asambleas. Analizo cómo eran un lugar intercambio, más que un espacio de decisión común, y cómo su dinámica era afectada por distintas tensiones y diferenciaciones. Muestro cómo las decisiones tomadas allí no siempre eran respetadas por todos los asambleístas. Los distintos sentidos en torno a la dinámica de las reuniones plenarias no se circunscribían a una delimitación de un criterio metodológico común de funcionamiento, sino que implicaban una concepción política sobre las asambleas, que establecían ciertas relaciones de poder entre sus integrantes.

\section{El lugar de encuentro y discusión}

Uno de los primeros desafíos de los asambleístas fue encontrar una forma de organización que les permitiera conversar entre ellos. Experiencias políticas anteriores, conocimientos profesionales y el sentido común de cada uno se pusieron en juego para poder constituir una forma de organización que les permitiera escucharse y tomar las primeras decisiones. Quién habla primero, cuánto tiempo y cuándo se puede interrumpir, fueron los primeros acuerdos. No obstante, más allá de las dificultades, la mayoría de los participantes coincidió en que lo "realmente" importante era poder "compartir ese momento".

El primer paso fue elaborar una lista de oradores que estableciera un orden de intervención. Igualmente, decidieron elegir tres coordinadores por sorteo, rotativos, para 
que ordenaran la reunión. En ese proceso se fueron estableciendo códigos comunes de trabajo, y así se constituyó una rutina de funcionamiento. Las reuniones se iniciaban alrededor de las 21 horas y terminaban pasada la medianoche. Cualquier persona que se acercara podía opinar y votar en igualdad de condiciones.

En ellas se combinaban momentos de debate político y elaboración de iniciativas con la puesta en común de "sentimientos". En los primeros encuentros, lo que predominaba era la búsqueda por "compartir". Según los relatos de los protagonistas, cada uno expresaba sus opiniones sin buscar una decisión conjunta, privilegiando la posibilidad de conformar un relato testimonial que expresara qué estaba sucediendo en ese momento. Todos coincidieron en que lo "realmente" importante era poder "compartir ese momento", más allá de las limitaciones y dificultades de las reuniones.

Tal como señalaron, los problemas que debieron afrontar fueron, en primer lugar, poder escucharse entre todos combinando sentimientos, impresiones del momento y posiciones políticas e ideológicas. Las reuniones eran extensas, numerosas, y los temas para abordar, "interminables". En segundo lugar, cómo tomar decisiones colectivas, teniendo en cuenta la opinión de "todos".

Las herramientas conocidas por el activismo político fueron utilizadas para la organización de las reuniones: lista de oradores, tiempo estipulado de exposición, un coordinador rotativo para dar la palabra. Desde ahí fueron generando estrategias para lograr un mayor diálogo en las reuniones.

A medida que fueron pasando las semanas, se hicieron más significativos los requerimientos de discusión política y de organización de actividades. El funcionamiento en comisiones (salud, prensa, compras comunitarias) buscó profundizar el debate, así como preparar las iniciativas discutidas durante el plenario. Al final de la reunión general, cada comisión definía hora, día y lugar del próximo encuentro.

El argumento central para crear las comisiones fue que estas ayudaban a mejorar el funcionamiento de la asamblea. No obstante, no todos estaban de acuerdo con esta postura. Algunos asambleístas, como Adrián, creían que la formación de estas instancias era producto de la imposición de partidos como el Movimiento Socialista de los Trabajadores (MST) o el Partido Obrero (PO) para que se trataran temas que estos caracterizaban como relevantes, pero que no expresaban las inquietudes de los integrantes de la asamblea.

\begin{abstract}
Me daba la impresión de que muchas veces, como en la asamblea había de todo, a un grupo le interesaba trabajar más con los desocupados, entonces políticamente se simbolizaba una comisión con esa orientación digamos; pero no tanto como algo que tenía que ver con una necesidad de la asamblea. (Adrián, preceptor, integrante de la agrupación Socialismo Libertario, 40 años, asamblea Parque Díaz, Buenos Aires, junio de 2005)
\end{abstract}

Esta reflexión que Adrián planteó como un problema permite aproximarse a la multiplicidad de sentidos asignados al trabajo en comisión. Como surge de los distintos relatos, las comisiones fueron tanto una forma de dividir tareas y responsabilidades, acortar y agilizar las reuniones plenarias, como una manera de descomprimir ciertos debates e iniciativas cuando no todos estaban de acuerdo con la importancia o prioridad del tema en discusión.

Del mismo modo, mientras la concurrencia a las reuniones de la asamblea fue numerosa, el funcionamiento en comisiones permitió el intercambio y la elaboración de propuestas, demandas e iniciativas. La notoria heteregoneidad política, ideológica y 
2. En Argentina, las corrientes autonomistas recuperaron experiencias como el zapatismo en México, los movimientos "alterglobalización" y las instancias del Foro Social Mundial; y se referenciaron en trabajos elaborados en América Latina por autores como Ana E. Ceceña, Raúl Zibechi y John Holloway, y en producciones europeas como las de Tony Negri y Giles Deleuze (Bergel, 2007). Algunas de las organizaciones identificadas como autonomistas fueron el "Colectivo Situaciones", ciertas agrupaciones de desocupados como los MTD de Guernica, Río Negro y Solano, y diversos medios de comunicación alternativa, como "lavaca”. generacional se ponía en tensión en el debate sobre los modos de combinar problemáticas y demandas barriales y nacionales diversas. Como recordaba Eduardo: "en algunos momentos había debates de coyuntura política, nacional, pero en general, el ochenta por ciento era debate en torno a cosas muy pequeñas: hacemos un juego de llaves o no hacemos" (arquitecto, exactivista del centro de estudiantes de la universidad, 50 años, otra asamblea de la ciudad, Buenos Aires, marzo de 2005).

Por otra parte, aun cuando se lograra acordar ciertas formas de funcionamiento, la ausencia de un vocabulario común y claro para cualquier persona que pudiera acercarse, la utilización de siglas y abreviaturas y la referencia a distintas corrientes políticas y debates pasados dificultaba la intervención de quienes no tenían experiencia política previa; por ejemplo, cuando se mencionaban corrientes políticas o siglas de organizaciones partidarias que no siempre eran conocidas por todos sus integrantes. Incluso algunos que ya tenían alguna trayectoria o formación política previa alertaban sobre la dificultad de entender las diversas intervenciones.

Inmediatamente empezaron a circular toda una serie de abreviaturas, siglas, conceptos, ideas, abstracciones políticas y demás que para alguien que no está en tema no sabe de qué se está hablando [...] Me perdía yo, me imagino un vecino: llega y no sabe de qué estás hablando, no sabe si es un congreso de física nuclear o están hablando de política [...] Gente hablando de no, porque tal es morenista. ¿A quién le importa hoy el morenismo? Literalmente, yo no tengo claro bien qué es el morenismo, ni me importa tenerlo, porque es algo irrelevante. Me imagino una persona que a duras penas sabe qué significa el MST, qué puede saber qué es el morenismo. (Esteban, docente universitario, exactivista del centro de estudiantes del secundario y de la universidad, 35 años, asamblea Parque Díaz, Buenos Aires, septiembre de 2005)

Valorada como una tarea difícil, la búsqueda de nuevas formas de relación, debate y decisión fue subrayada por algunos asambleístas como "la primera vez que se desplegó de manera abierta el método asambleario y de la acción directa, la crítica a la noción de representación y a las jerarquías". (Esteban, docente universitario, exactivista del centro de estudiantes del secundario y de la universidad, 35 años, asamblea Parque Díaz, Buenos Aires, septiembre de 2005)

Ciertas ideas y propuestas denominadas como autonomistas jugaron un significativo papel en las discusiones y discursos de gran parte de las asambleas. Como señaló Thwaites Rey (2004), al igual que en otras organizaciones sociales y políticas, en muchos asambleístas primó la idea de que la "emancipación social” no debía tener como eje central la "conquista" del Estado. Si bien no podría definirse como una corriente política o de pensamiento precisa, a los fines de este trabajo nos interesa señalar que estos discursos, articulados sobre la noción de "autonomía”, se centraron en las prácticas políticas "horizontales", la toma de decisiones por consenso y el rechazo de las formas de representación política. ${ }^{2}$

Al mismo tiempo, uno de los ejes centrales de las asambleas fue la crítica a la noción de representación política. De esta manera, cuestionaban la legitimidad de la metáfora representativa (Abal Medina, 2004) característica de la democracia moderna como mecanismo capaz de presentar "lo social en lo político" por medio de los partidos políticos y las elecciones periódicas. En ese proceso, las asambleas señalaban cómo el sistema de representación se orientaba hacia su autorreferencialidad, lo cual lo iba debilitando. Promovían prácticas y propuestas que buscaban otros modos de interacción y relación entre lo social y lo político que, si bien se distinguían de las formas de organización tradicionales, mantenían puntos en común y tensiones características de otros ámbitos colectivos. 


\section{Dificultades y tensiones entre sus integrantes}

Las asambleas fueron un espacio heterogéneo, atravesado por diferencias de edad, profesión, trayectoria y género. Esas diferencias resultaron sustantivas al momento del uso de la palabra y la toma de decisiones, lo que generó una serie de tensiones y conflictos que afectaron su dinámica de funcionamiento. Para abordar algunos aspectos de esta problemática, en este punto del trabajo analizo el desarrollo de algunas actividades en las que se pusieron de manifiesto disputas de poder y vínculos asimétricos entre sus integrantes que, en algunos casos, la propia dinámica fue asimilando y resolviendo pero, en otros, terminó con la disminución de la participación en la asamblea o directamente con el apartamiento de algunos integrantes. La reconstrucción del proceso y el análisis de los datos dan cuenta de que estas situaciones evidenciaban las diferentes concepciones políticas en juego sobre las asambleas y establecían ciertas relaciones de poder entre sus integrantes.

Uno de los conflictos que surgieron reiteradamente fue la administración y el uso del local de la asamblea. Para algunos asambleístas, ese espacio solo podía utilizarse para actividades "políticas". Sin embargo, otros consideraban que también podían desarrollarse otro tipo de actividades culturales y festivas. Si bien algunos afirmaban que tenía que ver con el cuidado del espacio frente a la posibilidad de su clausura o desalojo, otros creían que era un problema generacional. Este debate revelaba la tensión sobre el carácter político y social que debía tomar el ámbito colectivo.

El uso del predio sobre todo: para fiestas no, alcohol no [...] En cuestiones con las que uno por ahí no tiene ningún problema moral pero que los viejos sí tienen, como el escabio, con que no se fume. Algunas cuestiones que desde un punto de vista eran por un problema de seguridad de la asamblea, no darle a nadie ninguna excusa como para que la cerraran, nos desalojaran del predio ni nada. Entonces, en función de eso había algunos recaudos que había que tomar que estaban bien, pero por ahí el sector de gente más grande lo cuestionaba más por el lado moral. Aparte que en algunos momentos de discusión los callaban, en un momento eso explotó. (Agustín, estudiante universitario, integrante del Partido de los Trabajadores Socialistas (PTS), 30 años, asamblea Parque Díaz, Buenos Aires, diciembre de 2005)

En otros casos, algunos integrantes consideraban que las actividades tenían distinto valor y jerarquía dentro de la asamblea. Desde la comisión de educación, Marina consideraba que su trabajo era subestimado por los mayores. Dictaba clases de "apoyo escolar" para quince niños con problemas de distinto orden, quienes querían reunirse "como los grandes". Necesitaba ayuda para su propuesta de organizar la "asamblea de los pibes":

Recuerdo que en las asambleas yo decía: bueno, yo tengo información sobre la comisión de educación y todos ponían cara de ternura, y ino era una cuestión de cara de ternura, loco! ¡Yo laburaba con pibes que eran abusados sexualmente, laburaba con niños que tenían que laburar, y necesitaba apoyo, tenía 19 años, 2o! [...] Los niños quisieron participar de la asamblea de grandes y yo, cuando lo comenté en la asamblea, como que todo el mundo se rio. (Marina, estudiante, sin experiencia política, 22 años, asamblea Parque Díaz, Buenos Aires, agosto de 2005)

El problema era cómo los integrantes regulares de la asamblea consideraban la tarea de apoyo escolar, no necesariamente una cuestión generacional.

En otro caso, las divisiones en comisiones imprimieron una dinámica particular a cada grupo, que podía verse alterada al momento de integrarse otros asambleístas. Este fue el caso del Micrófono Abierto. Este se organizaba una vez por mes en algún bar del barrio 
y consistía en poner a disposición un micrófono para quien quisiera. Cantaban, recitaban o leían. Concurrían los integrantes de la comisión y amigos que ellos invitaban.

La Comisión de Juventud, por su parte, estaba compuesta mayoritariamente por personas que promediaban los veinte años, pero también estaba integrada por asambleístas de treinta o cuarenta años. Al igual que Parque Díaz, en general sus iniciativas eran de carácter cultural y/o festivo.

Los muy jóvenes, de entre 18 y 23, éramos muy pocos [...] siempre caía alguien. Había un grupo que se mantenía pero caían a comer pizza. [...] Era como un vermú. Y gente estaban Mariano, Pedro que tenía 37, ahora debe tener 40. Éramos un grupo de diez como mucho. (Micaela, exactivista del centro de estudiantes secundario, 18 años, asamblea de San Lorenzo, Buenos Aires, febrero de 2006)

Josefina describe cómo el día que la Comisión de Juventud participó del Micrófono Abierto irrumpió en un espacio ajeno con una dinámica diferente a la que acostumbraban.

Ahí la comisión de juventud nunca participaba. Pero ese día fueron y leyeron la carta de Rodolfo Walsh, nos mataron... Esta cosa de las organizaciones estudiantiles, ¿viste? [...] Era como el espacio donde íbamos a divertirnos y bueno, fue un bajón eso. Los jóvenes estaban haciendo esta militancia universitaria, que capaz que alguno estaba en el secundario todavía, pero esta cosa muy afín a la muerte y al sufrimiento que por ahí es algo propio de la adolescencia igual. (Josefina, estudiante universitaria, exintegrante de una agrupación universitaria trotskista, 30 años, asamblea de San Lorenzo, Buenos Aires, junio de 2005)

En este relato se puede observar cómo los jóvenes aparecen como un "otro" diferente. Ellos parecen haber transformado el momento de la dispersión impregnándole el "bajón del militante". Josefina relacionaba esta actitud con una característica de la juventud, del activismo político universitario del cual había formado parte, pero con la que ya no se identificaba. Sin embargo, el punto central parece la dificultad que se produjo cuando un grupo de personas que eran parte de otra comisión propuso una dinámica diferente a la acostumbrada.

También las actividades desarrolladas permitieron integrar miradas y perspectivas. Luego de los primeros meses de trabajo, las asambleas reorientaron gran parte de su tiempo a llevar adelante en sus barrios diversas actividades culturales, educativas y festivas. En la asamblea Parque Díaz crearon la comisión de contrakultura. Este espacio se proponía realizar actividades diferentes a las usuales en la "cultura de izquierda". Una de sus primeras iniciativas fue organizar una serie de encuentros con movimientos sociales. Para la primera charla invitaron a organizaciones "lésbico-gays". Aunque criticada por algunos asambleístas, fue una instancia donde algunos se permitieron un espacio para la reflexión. Como recuerda Esteban, ese fue el caso de Rodolfo, un asambleísta muy activo de ochenta años que intentaba, según sus palabras, "aprender de la juventud":

Él escuchó, escuchó a los chicos hablar de sus luchas, de sus problemas cotidianos y en un momento pidió la palabra y dijo que para él... o sea, pidió disculpas, que él por su vocación no entendía bien esto, pero en algún lado había entendido que esa gente tenía una razón para estar peleando por lo suyo y que había que tirarles buena onda. (Esteban, docente universitario, exactivista del centro de estudiantes del secundario y de la universidad, 35 años, asamblea Parque Díaz, junio de 2004)

En el desarrollo de las asambleas y sus actividades surgieron distintas situaciones que generaron altos niveles de conflictividad: las iniciativas de la comisión de cultura, el 
consumo de marihuana, las actividades durante los festivales, la convivencia en el local, la "asamblea de los pibes", entre otros temas, fueron abordados de distintas maneras. En algunos relatos y reconstrucciones, estos hechos se identifican como problemas en los vínculos entre jóvenes y mayores. Sin embargo, una mirada global sobre el proceso da cuenta de que tensiones o conflictos que algunas veces eran explicados como cuestiones de edad, con miradas estigmatizadas y prácticas discriminatorias, de fuerte contenido moral hacia los jóvenes, tenían que ver con la mirada y las expectativas que los propios integrantes tenían de su participación en las asambleas.

La asamblea de San Lorenzo había resuelto no tener un local propio, por lo cual solicitaba distintos espacios del barrio cuando requería un lugar cerrado. Una gran parte de las reuniones llevadas a cabo durante el invierno de 2002 se realizó en una iglesia luterana ubicada en la esquina del lugar habitual de las reuniones.

Paralelamente, la asamblea utilizaba la casa de un asambleísta, Arnaldo, que vivía cerca y estaba dispuesto a prestar su vivienda. En febrero de 2003 ocuparon la vivienda de Arnaldo, y la transformaron en la "casa de la asamblea" para intentar evitar que su compañero fuera desalojado.

En la reunión plenaria, los asambleístas decidieron por mayoría ocupar la casa para conservarla como "centro cultural de la asamblea", a pesar de que no todos los integrantes estaban de acuerdo con la medida. Luego suspendieron la reunión y se dirigieron al lugar. Algunos, como Luisa, consideraban que la decisión había sido muy repentina.

Bueno, lo que ocurrió realmente fue que ese jueves -vos no fuiste- [se refiere a Fernando] y fui yo, y yo me sentí re mal, porque sentí como que vinieron y dijeron: acá lo central es que a Arnaldo lo van a desalojar y nosotros tenemos que tomar la casa para impedir que lo desalojen y convertir ese lugar en la casa de la asamblea. Entonces, de repente se levantó la reunión de esa esquina y todo el mundo fue para allá [...] fue un desbande, porque los que no estábamos de acuerdo... Yo fui pero en disidencia, digamos... (Luisa, psicóloga social, exintegrante del Partido Revolucionario de los Trabajadores [PRT], 56 años, as amblea de San Lorenzo, Buenos Aires, noviembre de 2004)

Como consecuencia, durante los casi tres meses que duró la ocupación, la asamblea cambió su dinámica y dejó de funcionar en su tradicional esquina para trasladarse a esa casa.

Sin embargo, el debate interno en relación con esta decisión continuó y se incorporó al boletín de la asamblea del 21 de mayo de 2003. Tras la controversia causada por un artículo escrito por uno de los asambleístas, la asamblea decidió en la reunión plenaria "censurar" este contenido retirando la revista de circulación. Esa nota cuestionaba la ocupación de la siguiente manera:

¿Puede una asamblea entera, en un rapto de solidaridad (o simplemente de mezcla culposa de lavado de conciencia, porque, quién sabe qué haríamos si estuviéramos del otro lado de la antinomia, si se me permite una digresión al respecto) apoyar a un vecino en situación de desalojo, sin discutir seriamente por ejemplo sobre la maldita propiedad privada y mentirse a sí misma alevosamente durante tanto tiempo, ignorando aparentemente los hechos que se esconden detrás de esta historia? ¿Puede una asamblea combativa estar hace más de dos meses debatiendo casi exclusivamente sobre esto? ¿Podemos gestionar ante quien corresponda (por ejemplo CGP, etc.), cuando nos declaramos autónomos y horizontales? ¿O será que tenemos que confesar y asumir una vez más que la necesidad tiene cara de hereje? 
¿Es posible que pongamos en segundo plano y hasta posterguemos actividades indispensables que tienen que ver directamente con la historia actual de nuestro país, que lisa y llanamente nos está pasando por arriba? Creo que no. (Boletín de la asamblea, del 21 de mayo de 2003)

Este artículo resumió los principales núcleos del debate en torno a la ocupación: la propiedad privada, la relación con el Estado, la "necesidad" de un local propio y la toma de decisiones. El intento de "solidarizarse" con Arnaldo forzó una resolución en torno al tema de la ocupación para tener un espacio "propio", que en la asamblea de San Lorenzo parecía haberse saldado tiempo atrás. A su vez, Arnaldo representaba el vínculo con el "otro", con otros sectores sociales que en general no eran parte de la asamblea.

Finalmente, Arnaldo fue desalojado en mayo. Sin embargo, el juez que dictó la orden de desalojo hizo lugar al reclamo de la asamblea y solicitó al Gobierno de la Ciudad que cediera un local para realizar las actividades. Pero esta posibilidad ya no interesaba a los asambleístas; días antes del desalojo habían decidido dejar la casa debido a conflictos internos, y retornar a la esquina habitual de reuniones. Ese mismo mes realizaron sus últimas reuniones y actividades, hasta que la asamblea terminó por disolverse.

La dinámica cotidiana puso en tensión diferentes sentidos, saberes, prejuicios, trayectorias, conocimientos y prácticas. Esas tensiones y conflictos muestran en las dos asambleas la gravitación de relaciones de poder que, como señaló Foucault, constituyen "los efectos inmediatos de las particiones, desigualdades y desequilibrios que se producen, y recíprocamente son las condiciones internas de tales diferenciaciones" (Foucault, 2003, p. 114). Su peso en las relaciones e interacciones cotidianas promovió el distanciamiento de algunos integrantes de las asambleas.

\section{"La máquina de votar"}

Como señalamos al inicio de este trabajo, en un comienzo las asambleas eligieron el voto a mano alzada como método de decisión. El coordinador o los coordinadores designados para cada reunión preguntaba quién votaba por la afirmativa, quién por la negativa y quién se abstenía, y luego contaba los votos. Todo lo que se hablaba era puesto a consideración en el plenario. Sin embargo, como relató Luisa, esa forma de decisión no implicaba necesariamente que las iniciativas votadas fueran a llevarse a cabo.

Son cómicas algunas cosas que hacíamos en la asamblea, como eso que te decíamos de: hay que votar si vamos a ir a Parque Centenario. Entonces contábamos los votos y por mayoría salía votado que íbamos a ir a Parque Centenario ¿Quién va a ir?... nadie quería ir... (Luisa, psicóloga social, exintegrante del Partido Revolucionario de los Trabajadores [PRT], 56 años, asamblea de San Lorenzo, Buenos Aires, junio de 2004)

Frente a este escenario, los asambleístas fueron definiendo nuevos criterios para la toma de decisiones. El que presentara una propuesta al plenario luego sería responsable de que fuera llevada a cabo, en caso de que la asamblea diera su aprobación: "el que lo dice, lo hace".

Un foco relevante de discusión giró alrededor de cuál era el momento apropiado para resolver una actividad y quiénes eran los indicados para aprobarla o desaprobarla. Algunos afirmaban que las decisiones sólo debían tomarse en los plenarios y sobre todo por consenso, tal como relató Esteban:

Yo varias veces traté al principio de proponer que trabajemos por consenso, pero en el clima de hostilidad que había era muy difícil. Pero yo trataba, aunque sea yo 
mismo, tratar de actuar con ese principio en dos sentidos: primero, no decidirlo en cosas que no me van a involucrar luego a mí poniendo el cuerpo, y dejando que si hay alguien que quiere hacer algo, yo no estoy de acuerdo o no creo en ello, pero no me parece particularmente mal, no joder. (Esteban, docente universitario, exactivista del centro de estudiantes del secundario y de la universidad, 35 años, asamblea Parque Díaz, Buenos Aires, diciembre de 2005)

Otros proponían que la última palabra la tuvieran quienes fueran parte de cada iniciativa. Que fueran ellos los que finalmente decidieran en ese momento si se hacía o no la actividad que se había propuesto. Roberto sostenía esta última postura, buscando que las prácticas de las asambleas "no repitieran" modos burocráticos y jerárquicos de los sindicatos en sus formas de funcionamiento:

Yo hice referencia a que me hacía acordar cuando [el dirigente sindical] Lorenzo Miguel largaba el paro, que lo votó supuestamente en el consejo directivo [del sindicato], y después se aplicaba mecánicamente. Las medidas tienen que ser votadas en el momento con la gente que la hace, no son por transmisión o por decreto. (Roberto, plomero, exintegrante del Movimiento al Socialismo [MAS], 60 años, asamblea Parque Díaz, Buenos Aires, noviembre de 2005)

La "máquina de votar" fue perdiendo importancia para los propios protagonistas, pues la toma de decisión sobre ciertos temas se convirtió, para la mayoría de sus integrantes, en una mera formalidad. Con el paso de los meses, no todas las mociones puestas a consideración en el plenario cobraban la misma relevancia. En general, las actividades vinculadas al barrio se resolvían más rápidamente que las orientadas a cuestiones de política nacional. Del mismo modo, algunas mociones se proponían sabiendo que iban a ser aprobadas con facilidad, como las propuestas de "solidaridad" con la "lucha" de alguna organización o el repudio a alguna acción represiva policial. Frecuentemente, el momento de la votación sólo implicaba lograr el "aval” de la asamblea para alguna acción organizada por otro grupo.

Para Humberto, el voto nunca definió las acciones de la asamblea, pues en la mayoría de las iniciativas llevadas a la práctica no era "necesario" que fueran sometidas a votación. Solía suceder que algunos asambleístas acercaban sus propuestas a la reunión, tras lo cual quienes estaban interesados se sumaban a ellas, sin que necesariamente estas fueran puestas a consideración del plenario: "la mayoría de las actividades que se hicieron no se votaron. [...] Por ejemplo, este sociólogo dijo: yo voy a hacer una encuesta, ¿quién se prende? Nos juntamos en el bar" (Humberto, 45 años, músico y psicólogo social, activista social, asamblea de San Lorenzo, Buenos Aires, junio de 2005).

Como se ha expuesto, el proceso de toma de decisiones no era igualmente valorado por todos los asambleístas; si bien importante, revestía distinta relevancia y alcances para cada uno. Una mirada de conjunto permite mostrar diferentes voces en una lógica que da cuenta de tensiones y matices. Así, mientras Luisa advertía que no todas resoluciones de la asamblea eran llevadas a cabo, Rubén señalaba la consigna "el que lo dice, lo hace" como una estrategia para garantizar la ejecución de las medidas votadas. Los relatos de Esteban y Roberto incorporaron el problema sobre cuándo y dónde se decidía, al tiempo que Luisa describió cómo el proceso de toma de decisiones se fue formalizando, perdiendo importancia para sus protagonistas y cómo pasó a ser una "ficción" y/o simplemente una forma de conseguir el "aval" de la asamblea. Por último, Humberto llegó a afirmar que el voto no era el que definía las acciones.

El proceso de toma de decisiones de las asambleas se basó en una conjunción de diferentes sentidos en torno a la implicancia y alcance de las resoluciones tomadas entre "todos". La diferencia central radicaba en cuál era el poder de decisión de cada 
3. Este espacio se conformó para debatir y elaborar un proyecto de ley de reglamentación del gobierno comunal en la ciudad de Buenos Aires. Junto con organizaciones de la sociedad civil y partidos políticos, participaban de las reuniones integrantes de algunas asambleas, generalmente en representación de sus asambleas, y otras veces, a título personal. integrante como parte del plenario y en qué medida esa misma persona que podía decidir y votar debía luego supeditarse a la decisión del espacio colectivo. En esa discusión se ponían en juego diferentes concepciones y expectativas sobre el carácter y alcance de la asamblea.

Algunos integrantes naturalizaban estas diferencias sobre el funcionamiento como parte de una "práctica autónoma". Esta era caracterizada por la ausencia de una organización jerárquica y de una relación de autoridad entre lo que definía el plenario y la acción individual o grupal de cada asambleísta. Desde este punto de vista, los integrantes no debían ser sancionados por no llevar adelante una iniciativa decidida en la reunión general, al tiempo que estos podían realizar acciones que no hubieran sido aprobadas en el plenario.

Porque en realidad nosotros con la asamblea empezamos a hablar de las asambleas autónomas, autónomo en este sentido de tener la capacidad... o sea, que el poder lo tiene uno solo, no que lo tiene un órgano o directivo, que no tenés que responder a otra cosa. [...] En la asamblea éramos eso, nosotros no respondíamos a ningún poder. [...] Desde el lugar de la autonomía, nosotros decíamos la asamblea decide esto; ahora si hay un grupo que quiere tomar un local, que lo tome. Eso era para nosotros la autonomía, o sea que si había un grupo que quería hacerlo, igual lo iban a hacer, no es que nosotros le íbamos a decir que no lo hicieran. (Josefina, estudiante universitaria, exintegrante de una agrupación universitaria trotskista, 30 años, asamblea de San Lorenzo, Buenos Aires, abril de 2005)

Para Eduardo, la propia composición y objetivos de la asamblea era lo que no permitía que hubiera decisiones comunes, ya que sus fines eran diferentes a los de un partido político. Este fue el caso de la discusión sobre la posición de la asamblea frente a las elecciones presidenciales de 2003.

Ese tipo de consensos en torno a quién votar [para las elecciones presidenciales] es más de un partido político o de un movimiento social de otras características, pero no de una asamblea. Las asambleas son habitualmente muy plurales, es imposible llegar a un consenso de ponernos todos de acuerdo y votar todos a uno, no. (Eduardo, arquitecto, exactivista del centro de estudiantes de la universidad, 50 años, otra asamblea de la ciudad, Buenos Aires, noviembre de 2004)

La asistencia al Espacio por Comunas ${ }^{3}$ resultó una cuestión significativa para entender estas dinámicas en la asamblea Parque Díaz. Rodolfo era el representante de la asamblea en ese ámbito; ocasionalmente lo acompañaba otra persona, pero él era el único que solía concurrir a todas las reuniones. Luego de un momento de auge, organización de actividades y movilización en torno a la ley de descentralización política de la ciudad de Buenos Aires, este espacio pareció estancarse. Sus informes se hicieron cada vez menos trascendentes para los asambleístas. Lo dejaban para el final y en general se dedicaban a escuchar lo que él transmitía. En marzo de 2004, Rodolfo, cansado de que lo escucharan "de compromiso", planteó a la asamblea si realmente estaba interesada en integrar el Espacio por Comunas. De ser así, él no seguiría siendo su representante. Este problema particular disparó una discusión que puso de manifiesto la forma de funcionamiento que desde hacía tiempo practicaba la asamblea. Los integrantes de Parque Díaz no concordaban respecto de cuáles eran los temas más importantes para el espacio; sin embargo, todos coincidían en que eso no impedía ni la discusión ni que perdurara el colectivo. Cecilia abrió el debate:

Hay que tener en cuenta la relación entre lo que se dice y lo que se hace. Este no es un partido político, es una asamblea popular. Cada uno hace lo que puede según sus posibilidades. Tanto comunas como privatizadas es la forma de vincularnos 
con el barrio. No solo mediante un volante sino con el trato personal. Levantemos la mano para ver quiénes están dispuestos a participar de este trabajo. (Cecilia, jubilada, integrante del Partido Comunista [PC], 70 años, asamblea Parque Díaz, Buenos Aires, noviembre de 2005)

Se podía observar mucha atención y preocupación. En ese marco, cada uno comenzó a intervenir diciendo qué le interesaba y porqué. Agustín, como integrante del PTS, sostuvo que era importante que cada asambleísta hiciera lo que quisiera según sus intereses, señalando las diferencias entre un partido y la asamblea. Para él, el tema de comunas no era prioritario.

No quiere decir que no colabore, pero no me puedo comprometer. Es buena la propuesta de que haya responsables según intereses y después puede haber voluntarios. Cada uno hace lo que quiere y algunas cosas vamos a poder hacerlas todos juntos. [...] Yo soy militante de un partido político y esto no es un partido. (Agustín, estudiante universitario, integrante del Partido de los Trabajadores Socialistas [PTS], 30 años, asamblea Parque Díaz, Buenos Aires, octubre de 2005)

Los integrantes de las asambleas concurrían a las reuniones de cada semana con diferentes expectativas. No todos esperaban ir para resolver con sus pares las actividades y acciones específicas de la semana.

Para mí es como que la asamblea el día jueves funcionaba más como un punto de encuentro. Después, si la asamblea no te daba el aval para hacer tal cosa, no lo hacías en nombre de la asamblea, pero lo ibas a hacer igual. Era más que nada eso: votar si se iba a usar el nombre de la asamblea o no muchas veces. (Andrea, estudiante, sin experiencia política, 22 años, asamblea de San Lorenzo, Buenos Aires, marzo de 2005)

El plenario como espacio para tomar resoluciones era relativizado. Para sus protagonistas, lo más importante de la reunión no era la posibilidad de tomar decisiones colectivas. Entonces, ¿cuáles eran los alcances de las reuniones de las asambleas? Tal como sugiere Ouviña (2002), lo más interesante no eran los plenarios en sí, sino los "bordes que se tejen, las redes, socializando experiencias e iniciativas varias" (p. 22). En palabras de Mariano:

Pasaba algo muy extraño, que era que había como un órgano deliberativo que era la asamblea donde se hablaba, y empezó a haber como una vida social alrededor que quizás hacía más a la asamblea que lo que pasaba. Siempre hubo esa contradicción, en algún sentido, que lo importante era votar en la interbarrial o lo importante era ese tejido vincular que permitía ese espacio social. (Mariano, Psicólogo, exactivista del centro de estudiantes, 40 años, asamblea de San Lorenzo, Buenos Aires, junio de 2005)

En síntesis, paralelamente a los plenarios, se fueron desplegando distintas iniciativas. Esas acciones podían ser producto de proyectos acercados al plenario y llevados adelante por las comisiones, o actividades organizadas por los propios protagonistas por fuera del plenario.

\section{Relaciones sociales, toma de decisiones y acción colectiva}

Los plenarios fueron un ámbito donde personas con diversas trayectorias y conocimientos construyeron una "práctica asamblearia” común. Como describí en este artículo, las asambleas se caracterizaron por la heterogeneidad de sus integrantes, la pluralidad 
de demandas y expectativas y la multiplicidad de debates políticos. En estos espacios, algunos asambleístas pudieron manifestar la "necesidad de encontrarse" y de expresar los sentimientos del momento. A su vez, en este marco emergieron diferentes conflictos.

Como mencioné, uno de los aspectos en los que se concentraron los estudios académicos y los trabajos políticos elaborados en las propias asambleas y otras organizaciones fue la "horizontalidad" de su funcionamiento. Esto suponía que las asambleas rechazaban las formas jerárquicas de organización, por lo que sus integrantes tomaban las decisiones entre "todos", mediante el voto por mayoría o por consenso. Sin embargo, en este trabajo mostré cómo la ausencia de jerarquías explícitamente establecida en las asambleas no fue sinónimo de horizontalidad, ni de ausencia de relaciones de poder, pues de todos modos continuó habiendo desigualdades. La voz de algunos integrantes no tenía el mismo peso que la de otros, lo cual derivó en muchos casos en que algunos asambleístas dejaran de concurrir. La reunión plenaria como mecanismo para la toma de decisiones, por otra parte, adquirió una complejidad mayor a la sostenida por estos estudios.

Tanto en la asamblea Parque Díaz como en la de San Lorenzo, la "práctica horizontal" y "autónoma" destacada por algunos de sus integrantes supuso una concepción diferente a la de otros espacios colectivos en los que muchos habían participado previamente. Así, los asambleístas conjugaron sentido común y saberes profesionales y de activismo político, dando significados a sus prácticas y proyectos, a la vez que complementando distintas formas de organización, vocabulario y tecnologías.

Los núcleos de discusión respecto del proceso de toma de decisiones pueden sintetizarse de la siguiente forma. Primero, cuál era la mejor manera de decidir, por consenso o mayoría. Segundo, cuándo y quiénes tomaban las decisiones. Tercero, qué temas debían votarse y cuáles no. El debate de fondo giraba en torno a la implicancia de las reuniones plenarias y sus resoluciones. Por un lado, no estaba claramente establecido si la libre acción de cada uno debía supeditarse al colectivo. No todos creían que un asambleísta que no acordara con una medida aprobada debía someterse a la decisión del colectivo, ya que en la práctica cada uno seguía manteniendo su individualidad. En ese marco, el funcionamiento mismo de plenario se ponía en duda en los términos de ¿para qué se discutían y aprobaban diversos temas en las reuniones plenarias si luego nadie garantizaba que las decisiones tomadas fueran a llevarse a cabo? El centro de la cuestión era, por lo tanto, en qué medida el plenario era un ámbito para la toma de decisiones o si su relevancia política radicaba realmente en ser un espacio de discursos, debates y encuentros.

Para comprender con mayor claridad este proceso, es dable recuperar uno de los aportes clásicos de la antropología en torno a las relaciones de reciprocidad e intercambio y la creación de obligaciones como principio para la producción y reproducción de relaciones sociales. Marcel Mauss (1979), en su trabajo Ensayo sobre el Don, analizó cómo en algunas sociedades "primitivas" el intercambio no tenía solamente un carácter económico sino que tenía una significación religiosa, mágica y económica, utilitaria y sentimental, jurídica y moral. Lo calificó como "un hecho social total". Este autor describió cómo estos intercambios -aunque parecían voluntarios-, en realidad eran obligatorios. Los intercambios no eran solo de bienes útiles económicamente; eran sobre todo gentilezas, festines, ritos, servicios militares e incluso personas. Así, por medio del concepto de "don", describió un sistema basado en la triple obligación de dar-recibirrestituir. En su análisis, mostró cómo lo importante no era la transacción económica en sí, sino lo que ella significaba: relaciones de obligación recíproca cuya función era unir a los grupos y dar solución a las hostilidades para mantener las relaciones entre diferentes grupos, tribus o sociedades. 
Siguiendo el trabajo de Mauss, en el caso de las asambleas, es posible proponer que las reuniones plenarias se constituían mediante un proceso de intercambio de ciertos "bienes": conocimientos y experiencias en la organización del uso de la palabra y la toma de decisiones, en el debate y la reflexión sobre la coyuntura política, en el diseño de actividades, la redacción de resoluciones y documentos, entre otros.

Ese intercambio no solo conformó los plenarios como un ámbito instrumental para la toma de decisiones colectivas, sino que, sobre todo, generó relaciones de reciprocidad y obligaciones recíprocas, no tanto en torno a actividades específicas, sino alrededor de vínculos personales que se fueron estableciendo entre los integrantes como parte de su vida cotidiana. En otros términos, en el desarrollo de las reuniones plenarias y las actividades se fue construyendo una red de relaciones recíprocas que sostenían el lugar de encuentro a partir del intercambio de "bienes". 4

Esta trama de relaciones de reciprocidad se hace más evidente si se tiene en cuenta la heterogeneidad de trayectorias personales, la multiplicidad de sentidos y objetivos, la diversidad de valoraciones sobre el espacio colectivo, la flexibilidad de reglas para la acción colectiva que pusieron de manifiesto las asambleas.
4. Bourdieu (1991), al analizar los procesos de poder, dominación y violencia simbólica en sociedades tradicionales, describió cómo el "don" construye relaciones de poder desde la generación de dependencias recíprocas. Sin embargo, allí señala, recuperando a Finley (1965), que el "don" también puede ser generoso: "a pesar de su aparente contradicción, (el don o la deuda) tienen en común el poder de fundar tanto la dependencia e, incluso, la servidumbre, como la solidaridad según las estrategias a las que sirven" (Bourdieu, 1991, p. 214). 


\section{Q Referencias bibliográficas}

»Abal Medina, J. M. (2004). Muerte y resurrección de la representación política. Buenos Aires: Fondo de Cultura Económica.

» Achilli, E. (1993). La cotidianeidad, algunas consideraciones teóricas metodológicas (Documento de trabajo elaborado para el concurso de profesora titular de la Asignatura Metodología). Escuela de Antropología, Facultad de Humanidades y Artes, Universidad de Rosario, Rosario, Argentina.

» Bergel, M. (2007). En torno al autonomismo argentino. Darío Vive, portal latinoamericano de crítica social y pensamiento plebeyo. Recuperado de http://www.dariovive.org/notas/ berguel1.html

» Bourdieu, P. (1991) El sentido práctico. Madrid: Taurus.

» Brandone, S, I., Castañeda, M.L. y Román, F. (2017). La larga experiencia asamblearia entre los pobres urbanos: las Asambleas populares de San Telmo y la Alameda. En M. Gómez y A. Massetti (Eds.), Los movimientos sociales de la década ganada (pp. 41-88). Villa María: Eduvim.

»De Sousa Santos, B. (2005). Reinventar la democracia. Reinventar el Estado. Buenos Aires: CLACSO.

»Di Marco, G., Palomino, H., Méndez, S., Altamirano, R. y Libchaber de Palomino, M. (2003). Movimientos sociales en la Argentina. Asambleas: la politización de la sociedad civil. Buenos Aires: Universidad Nacional de General San Martín.

»Dinerstein, A. (2004). Más allá de la crisis. Acerca de la naturaleza del cambio político en Argentina. Revista Venezolana de Economía y Ciencias Sociales, 1(10), 241-269.

»Dri, R. (2006). La revolución de las asambleas. Buenos Aires: Diaporías.

» Fernández Álvarez, M. I. (2012). ‘Luchar’ por trabajo, trabajar ‘luchando’: prácticas cotidianas de organización y demanda en una empresa recuperada de Buenos Aires. Revista Papeles de Trabajo, 23,11-23.

»Fernández, A. (2006). Política y subjetividad. Asambleas barriales y fábricas recuperadas. Buenos Aires: Tinta Limón.

» Finley, M. (1965). La servitude pour dettes. Revue d'histoire du droit francais et étranger, $63(2), 45-86$.

» Foucault, M. [1977] (2003). Historia de la Sexualidad 1. La voluntad del saber. Buenos Aires: Siglo XXI.

» Gledhill, J. (2000). El poder y sus disfraces. Perspectivas antropológicas de la política. Barcelona: Bellaterra.

» Grimberg, M. (2009). Poder, políticas y vida cotidiana. Un estudio antropológico sobre protesta y resistencia social en el Area Metropolitana de Buenos Aires. Revista de Sociologia e Política, 17(32), 83-94.

» Grimberg, M., Ernandez, M. y Manzano, V. (2011). Antropología de las tramas políticas colectivas. Estudios en Argentina y Brasil. Buenos Aires: Facultad de Filosofía y Letras, UBA-Antropofagia.

" Manzano, V. (2013). La política en movimiento. Movilizaciones colectivas y políticas estatales en la vida del Gran Buenos Aires. Buenos Aires: Prohistoria. 
» Mauro, S. y Rossi, F. M. (2015). The Movement of Popular and Neighborhood Assemblies in the City of Buenos Aires, 2002-2011. Latin American Perspectives, 42(2), 107-124.

» Mauss, M. (1979). Sociología y antropología. Madrid: Tecnos.

» Ouviña, H. (2002). Las asambleas barriales y la construcción de lo 'público no estatal': la experiencia en la Ciudad Autónoma de Buenos Aires. Informe final del concurso: Movimientos sociales y nuevos conflictos en América Latina y el Caribe. Buenos Aires: CLACSO.

»Pérez, G., Armelino, M. y Rossi, F. (2005). Entre el autogobierno y la representación. La experiencia de las asambleas en la Argentina. En F. Schuster, F. Naishtat, G. Nardacchione y S. Pereyra (Eds.), Tomar la palabra (pp. 387-414). Buenos Aires: Prometeo.

»Svampa, M. y Corral, D. (2002). Piquetes y asambleas. Buenos Aires: Cedes.

"Thwaites Rey, M. (2004). La autonomía como búsqueda, el Estado como contradicción. Buenos Aires: Prometeo.

»Triguboff, M. (2015) Asambleas populares tras la crisis de 2001. Buenos Aires: Imago Mundi.

»Zibechi, R. y Hardt, M. (2013) Preservar y compartir: bienes comunes y movimientos sociales. Buenos Aires: Mardulce. 
